\title{
Psychophysical workload of workers in Slovenia
}

\author{
Eva Boštjančič, Zala Slana \\ University of Ljubljana, Faculty of Arts, Department of Psychology, \\ Aškerčeva 2, 1000 Ljubljana, Slovenia \\ eva.bostjancic@ff.uni-lj.si; zala.slana@gmail.com
}

\begin{abstract}
Introduction: The psychophysical workloads with which an individual has to cope on a basis at their workplace are important for the employee as well as the employer. It is important to be aware of them, draw attention to them and strive to reduce their sources. The setting-up of programmes and procedures is an important factor in reducing negative effects on employees, as well as maintaining and increasing employees' mental and physical health. Methods: This article will present a short self-assessment scale of psychophysical health that enables us to evaluate the appearance of five of the most frequent psychosomatic problems experienced by employees $(\mathrm{N}=490)$. Results: In the research, we will analyse the presence of exhaustion, social behavioural disorders, physical disorders, depressive reactions, and fear and anxiety in different demographic groups and, at the end, we will connect the symptoms with the field of activity. Discussion and conclusions: Research has shown a link between demographic variables and exposure to psychophysical risks. There is a more straightforward connection with education (higher levels of education are connected to lower risk), while the connection with age and gender is not so clear. Psychophysical workloads are more frequent in construction, manufacturing, the information industry and the civil service.

Key words: psychophysical workload, health, workers, Slovenia
\end{abstract}

onditions in working environments today are dependent on wider environmental as well as social and economic factors. Working conditions comprise physical (e.g. working hours, work equipment) and social factors (e.g., management style, nature of interpersonal relations). All factors (Hupke, 2013, mentions content of work, workload, level of supervision, working hours, the working environment, work equipment, the worker's role, or- 
ganisational culture, mutual relations, career development opportunities, and work-life balance) can, to a certain degree, present psychosocial risks to workers. They are among the most important risks related to workplace stress and affect the psychological and physical wellbeing of workers, and have an impact on their behaviour. The consequences present themselves indirectly in the costs of treating sick workers and the phenomena of absenteeism and presenteeism, accompanied, in all such cases, by a reduction in productivity and efficiency (Sparks, Faragher and Cooper, 2001). The results of the fourth European Working Conditions Survey (Brun and Milczarek, 2007) showed that, in 2005, 20\% of workers from the EU and 30\% of workers from 10 new Member States believed that their health was being put at risk by stress at the workplace. In 2002, the annual economic cost of workplace stress in the EU was estimated at EUR 20 billion.

It is not only the working environment that creates precisely defined conditions for the occurrence of health risks on the part of workers; the nature of an individual's profession is also a factor. We have therefore decided to examine which demographic groups, which areas of activity and which professions are currently subject to the greatest levels of load and exposed to specific psychosocial risks in Slovenia.

\section{Most common health risks experienced by workers}

Some $25 \%$ of the European population suffers from depression (Albreht and Turk, 2010), which they characterise as feelings of sadness, loss of interest and of the capacity for happiness, feelings of guilt and low self-esteem. The major negative consequences of depression at the workplace are reduced productivity and high incidences of absenteeism and presenteeism (Evans-Lacko et al., 2016).

Anxiety is defined as a state of unpleasant restlessness and a tension arising from a feeling of threat without a clear awareness of the causes. A certain degree of anxiety can have a positive effect on an individual, with impatience, nervousness and alertness improving a worker's efficiency. A Dutch study (Hendriks et al., 2015) has shown that more severe symptoms of anxiety are linked to absenteeism and long periods of absence from work.

Fatigue at the workplace combines a serious lack of energy with a reduced ability to function, resulting in less energy and motivation to respond to or persist in a certain type of activity or conduct. Three sources of energy are associated with fatigue: physical, psychological and emotional (Frone and Tidwell, 2015). The emotional toll exacted by work is not only expressed in emotional fatigue, but also in physical and psychological fatigue. This indicates that emotional burdens operate more widely and in a more harmful way. As society currently requires ever-greater interaction, cooperation and team work from workers, interest in emotional fatigue has grown in recent times, as a result of the phenomenon of emotional exhaustion (Frone and Tidwell, 2015). 
Social behavioural disorders at the workplace are most commonly expressed in different forms of violence. Workers may be victims of verbal violence, bullying (mobbing) or even sexual or racial harassment (Fiseković, Trajković, Bjegović-Mikanović and Terzić-Supić, 2015). This is a serious social and health problem and one that affects the psychological and physical health of workers, on their wellbeing, and on their family and working environments.

\section{Measuring psychophysical workload}

Psychophysical workload means increased workload placed on an individual. Workload is defined as the physical and mental requirements related to the performance of specific tasks (Gudipati and Pennathur, 2016). The physical volume of work is the measurable part of the physical resources expended in the performance of a specific task. Numerous factors affect this, including the nature of the work, experience, motivation and environmental variables. Tools for assessing physical workload include the use of evaluation techniques, physical diagrams, biomechanical analyses, measurements of energy consumption and analyses of the Pain Assessment Scale (Melzack, 1975 in Gudipati and Pennathur, 2016).

Measuring mental workload is more difficult and is defined as the amount of cognitive work required for a person to complete a specific task within a specific period (Longo, 2016). In practice, psychophysical measurements such as heart rate and brain activity can be employed to measure an individual's mental workload, along with an assessment of task implementation (reaction time, etc.) and self-assessment questionnaires (Gudipati and Pennathur, 2016).

\section{Problem}

The purpose of the research was to establish how certain demographic variables affect psychophysical health at work. Borg et al. (200o) found, for example, that women were a higher risk group than men when it came to understanding their own health; they also had fewer opportunities to improve perceptions of their own health. We therefore designed two research questions:

- Which demographic groups in Slovenia are currently most exposed to psychophysical risks?

Which professions or professional groups report the highest psychophysical risks?

\section{Methods}

\section{Participants and procedure}

The questionnaire was completed by 490 workers (366 women and 124 men). Twenty per cent of participants belonged to the first age group (18-26). The highest proportion of participants belonged to the second age group (27-35, 
$44.5 \%)$, while the third age group (36-44) accounted for $20 \%$ of participants. The fewest number belonged to the 45 and over age group ( $15.7 \%$ of the sample).

University graduates accounted for $35.9 \%$ of participants, followed by those who had completed secondary school education (24.1\%) and academic technical education (18.4\%). Those who had completed primary school, vocational secondary school or college accounted for the fewest number of participants (o.6, 2.2 and $5.7 \%$ respectively). A total of $13.1 \%$ of participants had completed Master's or doctoral studies.

We classified professions into 21 groups in line with the Standard Classification of Activities from 2008 (SKD, Uradni list RS, 69/07 and 17/o8). Twenty-two per cent (the highest single proportion) of participants were engaged in professional, scientific and technical activities. Health and social work professions (15.9\%) and education (14.3\%) were also well represented. Trade and motor vehicle maintenance and repair accounted for $9 \%$ of participants, as did other business activities.

The data was collected with the help of an online questionnaire in which all questions had to be answered. We used social networks and the psihologijadela.com website to invite participants to take part.

\section{Aids}

We used the Psychophysical Health Scale, SPFZ-2; Majstorović, 2011), which allows individuals to assess their own psychophysical health. It comprises 15 assertions within the following five dimensions: physical health complaints (e.g. "Have you suffered from stomach or other digestive complaints in the last four weeks?”), fear and anxiety (e.g. “ Have you been fearful for no good reason in the last four weeks?"), depressive reactions (e.g. "Have you had trouble sleeping in the last four weeks?"), fatigue (e.g. "Have you noticed, in the last four weeks, that you are tired for no good reason?") and social behavioural disorders (e.g. "Have you become intolerant of others in the last four weeks?"). With the help of a four-point Likert scale, the individual estimated how many times in the last four weeks they had identified a certain health issue as affecting them (possible answers are "No", "Yes, but not often", "Yes, often" and "Yes, every day"). The reliability of the original scale was 0.85 (Popov et al., 2016) and the reliability of the Slovenian translation was 0.80 (Kuhta, 2016).

At the end, the participants inserted further information in the form of their sex, age, level of education completed, profession and group of activities in which they were employed.

For the basic overview of data we used simple descriptive statistics $(M$, $S D$ ) and skewness, kurtosis and Kolmogorov-Smirnov test - to test normality of distribution.

Hierarchical regression analysis has been used, where age and education were presented with the aid of »dummy« variables - reference group of education is primary school education and of age is 18-26 age group. The last two 
graphs are a simple representation of avarage score on each dimension between different activities (SKD).

\section{Results}

Table 1: Self-assessment of five dimensions of psychophysical health of all participants according to the SPFZ-2 scale.

\begin{tabular}{|c|c|c|c|c|c|c|c|c|c|}
\hline \multirow{2}{*}{ Dimension } & \multirow{2}{*}{$M$} & \multirow{2}{*}{$S D$} & \multicolumn{2}{|c|}{ Asymmetry } & \multicolumn{2}{|c|}{ Kurtosis } & \multicolumn{3}{|c|}{ Kolmogorov-Smirnov test } \\
\hline & & & As & SE & Spl & $S E$ & Statistics & $d f$ & $p$ \\
\hline $\begin{array}{l}\text { Physical health } \\
\text { complaints }\end{array}$ & 5.48 & 1.74 & 0.86 & 0.11 & 0.68 & 0.22 & 0.17 & 489 & o \\
\hline Fear and anxiety & 4.27 & 1.61 & 1.41 & 0.11 & 1.49 & 0.22 & 0.25 & 489 & o \\
\hline $\begin{array}{l}\text { Depressive } \\
\text { reactions }\end{array}$ & 4.22 & 1.28 & 1.28 & 0.11 & 2.70 & 0.22 & 0.23 & 489 & o \\
\hline Fatigue & 6.02 & 2.17 & 0.59 & 0.11 & -0.40 & 0.22 & 0.15 & 489 & o \\
\hline $\begin{array}{l}\text { Social behavioural } \\
\text { disorders }\end{array}$ & 6.21 & 1.50 & 0.63 & 0.11 & 0.16 & 0.22 & 0.18 & 489 & o \\
\hline
\end{tabular}

Table 1 shows the average results for all participants across the five dimensions of the Psychophysical Health Scale. They show that the most pronounced dimensions for the participants are fatigue and social behavioural disorders. The lowest average values were in the dimensions of depressive reactions and fear and anxiety.

The results are presented below using hierarchical regression analysis for all dimensions. All tables are included for the dimensions in which the statistical differences are significant. A model was used that included, step by step, education, followed by age and, at the end, sex.

For the dimension of physical health complaints, the hierarchical regression analysis showed that demographic variables explained 3\% of the differences, but the variance produced was not statistically characteristic regardless of the predictors included in the model.

The demographic variables for the fear and anxiety dimension (Table 2) explain $5 \%$ of the differences, where the inclusion of education and age in the model increases the percentage of the variance produced or the differences between people in the dimension in a statistically significant way. With the education variable, there is a statistically significant difference between individuals who have completed secondary school, academic technical, university or doctoral studies. In the fear and anxiety dimension, these individuals differ from those who have completed primary school in a statistically significant way. If we include the predictor of age in the model, we see that the percentage of the variance produced increases significantly.

For the dimension of fatigue, the hierarchical regression analysis also shows that demographic variables explain $3 \%$ of the differences, but the vari- 
ance produced is not statistically characteristic regardless of the different inclusion of the predictors in the model.

Table 2: Hierarchical regression analysis: prediction of the dimension of fear and anxiety based on education, age and sex.

\begin{tabular}{|c|c|c|c|c|c|c|c|c|c|}
\hline \multirow[b]{2}{*}{ Predictor } & \multicolumn{3}{|c|}{ Model 1} & \multicolumn{3}{|c|}{ Model 2} & \multicolumn{3}{|c|}{ Model $_{3}$} \\
\hline & $B$ & SEB & $\beta$ & $B$ & SEB & $\beta$ & B & $S E B$ & $\beta$ \\
\hline
\end{tabular}

\begin{tabular}{|c|c|c|c|c|c|c|c|c|c|}
\hline Vocational & -0.46 & 1.05 & -0.04 & -0.41 & 1.04 & -0.04 & -0.56 & 1.04 & -0.05 \\
\hline Secondary & -1.81 & 0.94 & -0.48 & -1.77 & 0.93 & -0.47 & -1.87 & 0.94 & $-0.50^{*}$ \\
\hline College & -1.46 & 0.98 & -0.21 & -1.42 & 0.97 & -0.20 & -1.49 & 0.97 & -0.21 \\
\hline $\begin{array}{l}\text { Academic } \\
\text { technical }\end{array}$ & -1.81 & 0.94 & -0.43 & -1.75 & 0.94 & -0.42 & -1.88 & 0.94 & $-0.45^{\star}$ \\
\hline University & -1.74 & 0.93 & $-0.52 \%$ & -1.76 & 0.93 & $-0.52 \%$ & -1.86 & 0.93 & $-0.55^{*}$ \\
\hline Master's & -1.48 & 0.96 & -0.25 & -1.54 & 0.96 & -0.26 & -1.67 & 0.96 & -0.28 \\
\hline Doctorate & -2.25 & 0.98 & $-0.30^{*}$ & -2.27 & 0.99 & $-0.30^{*}$ & -2.28 & 0.99 & $-0.31^{*}$ \\
\hline \multicolumn{10}{|l|}{ Age } \\
\hline $27-35$ & & & & $-0.52 \%$ & 0.20 & $-0.16^{*}$ & -0.53 & 0.20 & $-0.16^{\star}$ \\
\hline $36-44$ & & & & $-0.16^{*}$ & 0.24 & -0.04 & -0.19 & 0.24 & -0.05 \\
\hline 45 and over & & & & -0.42 & 0.25 & -0.10 & -0.41 & 0.25 & -0.09 \\
\hline \multirow[t]{2}{*}{ Sex } & & & & & & & 0.27 & 0.17 & 0.07 \\
\hline & 0.03 & & & 0.05 & & & 0.05 & & -0.05 \\
\hline $\mathrm{F}$ & $2.18^{*}$ & & & $2.77^{\star}$ & & & 2.52 & & \\
\hline
\end{tabular}

Notes: HLM, education and age are presented with the aid of "dummy" variables, where the reference group for the first is primary school education and the reference group for the second is the 18-26 age group.

${ }^{*} p<0.05,{ }^{* *} p<0.01$

Demographic variables in the depressive reactions dimension (Table 3 ) explain $2 \%$ of the differences, but the change is not statistically significant. With the inclusion of the variables of age and sex, there are, within Model 3, statistically significant differences between individuals who have completed vocational, academic technical, university and doctoral studies. Individuals who belong to these groups differ significantly from those who have completed primary school in relation to the depressive reactions dimension. Their result for the dimension is $\mathbf{1 . 7 4}$ lower than for those who have completed vocational studies, 1.58 lower than for those who have completed academic technical studies, 1.63 lower than for those who have completed university studies and 1.6o lower than for those who have completed doctoral studies. 
Table 3: Hierarchical regression analysis: prediction of the dimension of depressive reactions based on education, age and sex.

\begin{tabular}{|c|c|c|c|c|c|c|c|c|c|}
\hline \multirow[b]{2}{*}{ Predictor } & \multicolumn{3}{|c|}{ Model 1} & \multicolumn{3}{|c|}{ Model 2} & \multicolumn{3}{|c|}{ Model } \\
\hline & $B$ & SEB & $\beta$ & B & $S E B$ & $\beta$ & $B$ & $S E B$ & $\beta$ \\
\hline \multicolumn{10}{|l|}{ Education } \\
\hline Vocational & -1.67 & 0.83 & $-0.19^{*}$ & -1.69 & 0.84 & $-0.20^{*}$ & -1.74 & 0.84 & $-0.20^{\star}$ \\
\hline Secondary & -1.35 & 0.75 & -0.45 & -1.37 & 0.75 & -0.46 & -1.40 & 0.75 & -0.47 \\
\hline College & -1.27 & 0.78 & -0.23 & -1.3 & 0.78 & -0.24 & -1.32 & 0.78 & -0.24 \\
\hline $\begin{array}{l}\text { Academic } \\
\text { technical }\end{array}$ & -1.49 & 0.75 & $-0.45^{*}$ & -1.54 & 0.76 & $-0.47^{*}$ & -1.58 & 0.76 & $-0.48^{\star}$ \\
\hline University & -1.55 & 0.75 & $-0.58^{*}$ & -1.59 & 0.75 & $-0.60^{*}$ & -1.63 & 0.75 & $-0.61^{*}$ \\
\hline Master's & -1.29 & 0.77 & -0.28 & -1.34 & 0.77 & -0.29 & -1.38 & 0.77 & -0.30 \\
\hline Doctorate & $-1.50 \%$ & 0.78 & -0.25 & -1.60 & 0.79 & $-0.27^{*}$ & -1.60 & 0.79 & $-0.27^{*}$ \\
\hline \multicolumn{10}{|l|}{ Age } \\
\hline $27-35$ & & & & -0.01 & 0.16 & o & -0.01 & 0.16 & o \\
\hline $36-44$ & & & & 0.09 & 0.19 & 0.03 & 0.08 & 0.19 & 0.02 \\
\hline 45 and over & & & & -0.14 & 0.20 & -0.04 & -0.14 & 0.20 & -0.04 \\
\hline Sex & & & & & & & 0.09 & 0.14 & \\
\hline & 0.02 & & & 0.02 & & & 0.02 & & \\
\hline $\mathrm{F}$ & 1.03 & & & 0.42 & & & 0.41 & & \\
\hline
\end{tabular}

Notes: HLM, education and age are presented with the aid of "dummy" variables, where the reference group for the first is primary school education and the reference group for the second is the 18-26 age group.

${ }^{*} p<0.05,{ }^{* *} p<0.01$

The demographic variables for the social behavioural disorders dimension (Table 4) explain $26 \%$ of the differences, where the inclusion of all three variables in the model increases the percentage of the variance produced in a statistically significant way. With the inclusion of age and sex (Model 3), statistically significant differences are produced in all education groups. Individuals with an education level above that of primary school more rarely experience social behavioural disorders. The result for individuals in the 45 and over age group is 0.98 higher than that for individuals in the 18-26 age group, which shows that such behaviour is more common in this age group than it is among younger people. It is shown in this dimension that, with the inclusion of all variables, there are significant differences with regard to sex, with women achieving a o.64 higher result than men, which indicates that there is a statistically significant higher frequency of social behavioural disorders. 
Table 4: Hierarchical regression analysis: prediction of the dimension of social behavioural disorders based on education, age and sex.

\begin{tabular}{cccccccccc} 
& \multicolumn{3}{c}{ Model $_{1}$} & \multicolumn{3}{c}{ Model $_{2}$} & \multicolumn{3}{c}{ Model $_{3}$} \\
\hline Predictor & $B$ & SEB & $\beta$ & $B$ & SEB & $\beta$ & $B$ & SEB & $\beta$
\end{tabular}

\section{Education}

\begin{tabular}{|c|c|c|c|c|c|c|c|c|c|}
\hline Vocational & -16.46 & 1.55 & $-0.90^{* *}$ & -16.36 & 1.54 & $-0.90^{* *}$ & -16.72 & 1.54 & $-0.92^{\star x}$ \\
\hline Secondary & -16.88 & 1.39 & $-2.66^{\star *}$ & -16.94 & 1.39 & $-2.67^{* *}$ & -17.18 & 1.38 & $-2.71^{\star *}$ \\
\hline College & -16.43 & 1.45 & $-1.41^{\star *}$ & -16.53 & 1.44 & $-1.42^{* *}$ & -16.68 & 1.43 & $-1.43^{\star *}$ \\
\hline $\begin{array}{l}\text { Academic } \\
\text { technical }\end{array}$ & -16.93 & 1.40 & $-2.43^{* *}$ & -16.88 & 1.39 & $-2.42^{\star *}$ & -17.19 & 1.39 & $-2.46^{\star *}$ \\
\hline University & -16.85 & 1.39 & $-2.99^{\star *}$ & -16.75 & 1.38 & $-2.97^{\star *}$ & -16.99 & 1.38 & $-3.01^{\star *}$ \\
\hline Master's & -16.43 & 1.42 & $-1.66^{\star *}$ & -16.40 & 1.42 & $-1.66^{\star *}$ & -16.71 & 1.42 & $-1.69^{\star x}$ \\
\hline Doctorate & -16.58 & 1.46 & $-1.33^{* *}$ & -16.68 & 1.46 & $-1.33^{* *}$ & -16.71 & 1.45 & $-1.33^{\star *}$ \\
\hline
\end{tabular}

Age

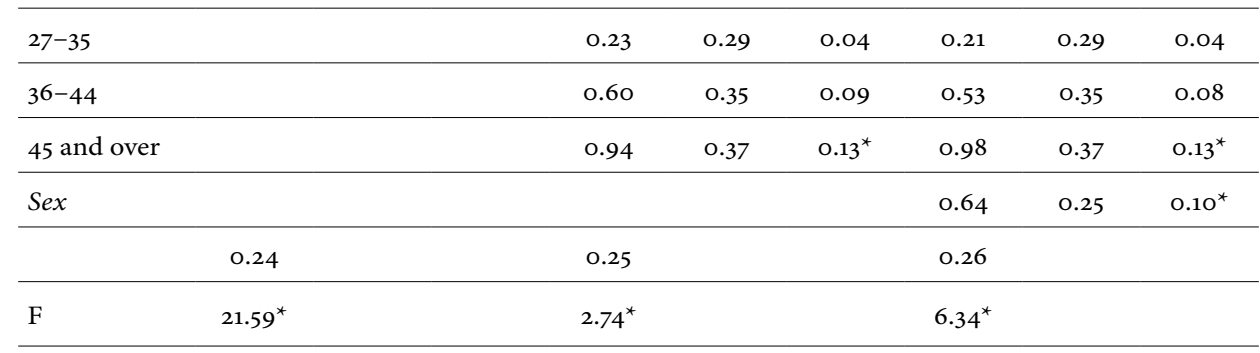

Notes: HLM, education and age are presented with the aid of "dummy" variables, where the reference group for the first is primary school education and the reference group for the second is the 18-26 age group.

${ }^{*} p<0.05,{ }^{* *} p<0.01$

The tables below show the frequency of psychophysical loads in relation to the area of work or activity under the SKD (Uradni list RS, 69/07 and 17/o8). Abbreviations are used for groups of activities in the tables for the purpose of transparency.

Physical health complaints (Figure 1) are most frequently reported by participants who perform work in construction $(M=6.00)$, followed by financial and insurance activities $(M=5.79)$. Participants engaged in electricity, gas and steam supply $(M=4.67)$ and cultural, entertainment and recreational activities $(M=4.91)$ report the lowest frequency of symptoms of illness.

The occurrence of symptoms linked to fear and anxiety is very low in the sample $(M=4.27)$. Individuals employed in trade and in motor vehicle maintenance and repair score highest above the average for this dimension $(M=4.80)$, followed by those engaged in manufacturing activities $(M=4.60)$. The absence of symptoms of fear and anxiety is described within the activity of electricity, gas and steam supply $(M=3.00)$. 


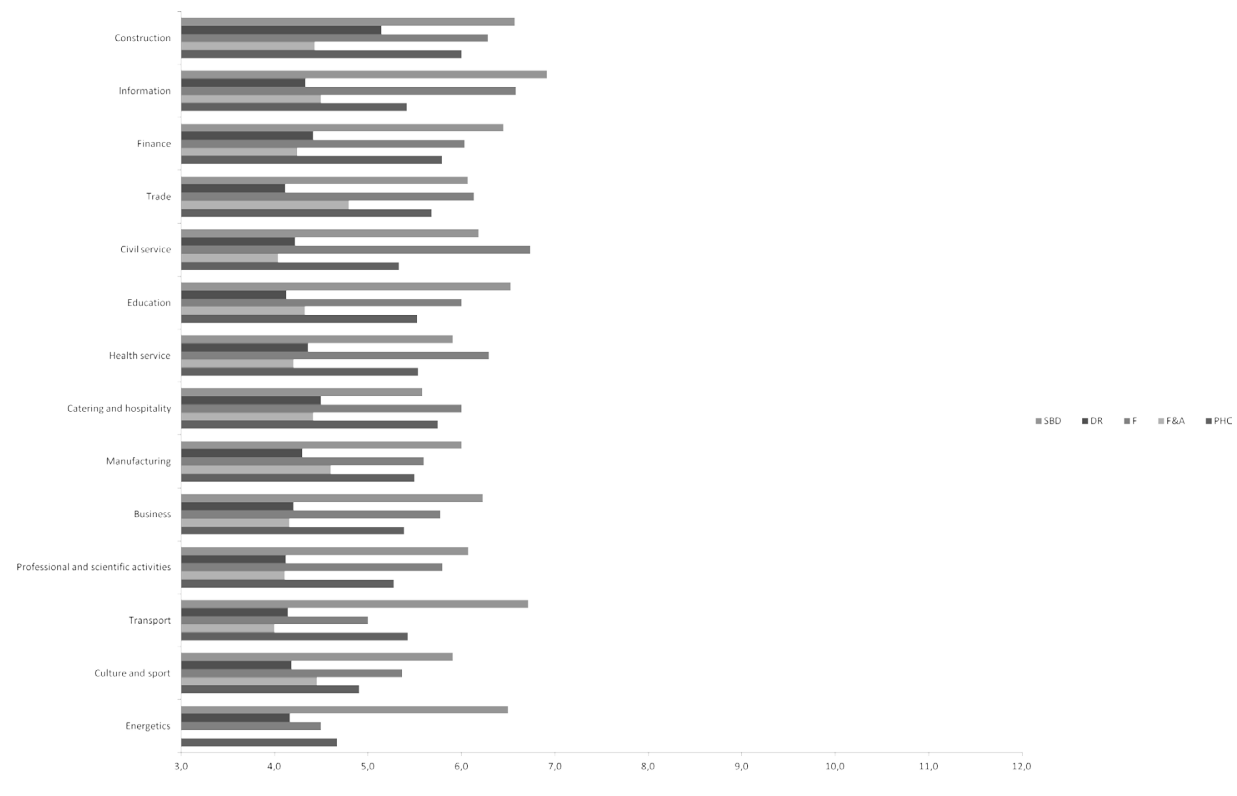

Figure 1: Occurrence of all five psychophysical load dimensions in different activities (SKD).

The dimension of fatigue has a high average value in comparison with other dimensions $(M=6.02)$. Individuals employed in public administration, defence and compulsory social security activities most frequently report symptoms linked to fatigue $(M=6.74)$, followed by those engaged in information and communications activities $(M=6.58)$. Symptoms of fatigue are rarely, if ever, reported by workers engaged in electricity, gas and steam supply activities $(M=4.50)$ and in transport and storage $(M=5.00)$.

Depressive reactions have the highest average value in comparison with the four other dimensions $(M=4.22)$. Symptoms are reported most frequently by those employed in construction $(M=5,14)$ and catering and hospitality $(M$ $=4.50)$. Never (or rarely) do symptoms occur in trade $(M=4.11)$ or in professional, scientific and technical activities $(M=4.12)$.

In our sample, social behavioural disorders appear with greatest frequency $(M=6,21)$. Workers in information and communications activities most frequently report intolerance and avoiding contact with others $(M=6.92)$, followed by transport $(M=6.71)$. By contrast, workers in catering and hospitality report positive experiences in relationships with others $(M=5.58)$.

A joint value on the Psychophysical Health Scale is given to enable a comparison between activities (Figure 2). The overall trend is similar to the trend observed in relation to individual dimensions: issues relating to psychophysical load are most frequently reported by workers in construction $(M=28.43)$. Information and communications activities $(M=27.75)$, financial and insurance activities $(M=26.93)$, trade $(M=26.80)$, public administration, defence and so- 
cial security activities $(M=26.52)$, education $(M=26.51)$, healthcare $(M=26.31)$ and catering and hospitality $(M=26.25)$ are all above the average for psychophysical health $(M=26.23)$. Participants employed in electricity, gas and steam supply $(M=22.83)$ and in cultural, entertainment and recreational activities $(M$ $=24.82$ ) enjoy the lowest levels of psychophysical risk.

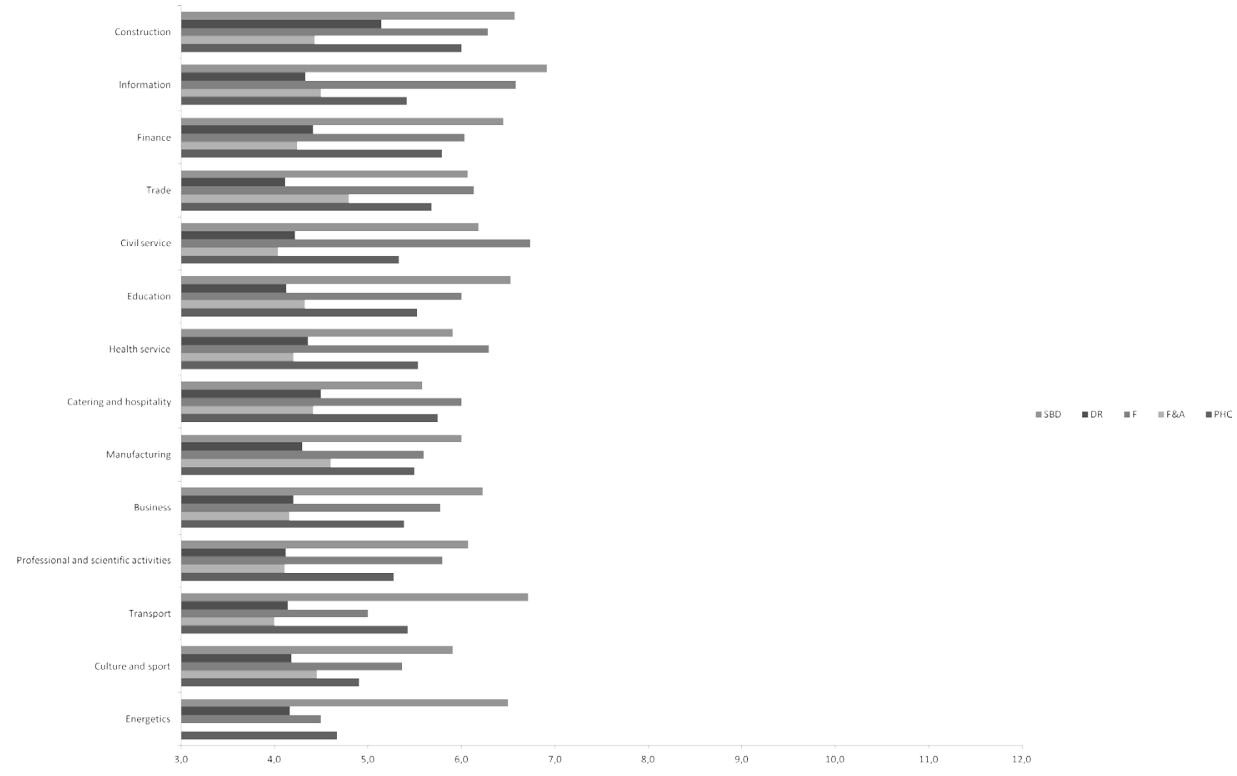

Figure 2: Presence of psychophysical load dimensions in different activities.

\section{Discussion}

The results show that the most pronounced dimensions for the actively working population are fatigue and social behavioural disorders. Participants therefore most frequently report fatigue, a lack of sleep, intolerance and the avoidance of social contact with others. Behaviour linked to the dimensions of depressive reactions and fear and anxiety is less frequent. Participants rarely mentioned groundless fear, fear of illness, loss of appetite and morbid depressive thoughts.

The purpose of the research was to establish a link between demographic variables and psychophysical health, i.e those demographic groups currently most exposed to psychophysical risks. The results show that we cannot use demographic variables to explain the differences between people in the dimensions of physical health complaints and fatigue.

With regard to the dimension of depressive reactions, and despite the fact that the model does not predict discrepancies in individuals' results in a statistically significant way, we can observe that there are differences in education. Individuals who have completed vocational, academic technical, university or higher studies report depressive symptoms less frequently (difficulties sleep- 
ing, reduced appetite and loss of a will to live). We can conclude in this case that education is a safety factor, as individuals with a higher level of education are less frequently exposed to depressive feelings.

The differences between individuals resulting from demographic variables are statistically important in the dimensions of fear and anxiety and social behavioural disorders. In relation to the dimension of fear and anxiety, there is also a trend for individuals with an education level higher than primary school to suffer significantly less fear and anxiety. There are also significant differences when it comes to age group, with individuals in the $27-35$ age experiencing fewer feelings of anxiety than their younger counterparts (18-26). Demographic variables have the greatest explanatory power with regard to the dimension of social behavioural disorders (they explain $26 \%$ of the variance). There are statistically significant differences with all three variables of education, age and sex for this dimension. Higher the education is, less symptoms are presented. This once again confirms the trend indicated: education as protective factor. There are also significant differences in age, as individuals over the age of 45 experience social behavioural disorders more commonly than those in the 18-26 age group. One can conclude, with regard to the age variable, that it is about the specificity of the age group in relation to the dimension and not the trend: individuals aged between 27 and 35 experience less anxiety, while social behavioural disorders are more commonly present among the over-45s. The results for the last dimension also show significant differences between the sexes: women report social behavioural disorders more frequently than men, and the difference is statistically significant. This connects with the findings of Borg et al. (2000), who found that women were a higher risk group than men when it came to understanding their own health. Given that this connection was evident in only one of the dimensions, we cannot fully support it.

The second part of our research question addresses the link between professional groups/activities and exposure to psychophysical risks. Participants who perform construction work most frequently experience physical health complaints, also employed in finance, insurance and catering and hospitality are more susceptible to feeling unwell. Symptoms linked to fear and anxiety are most frequent in trade and in motor vehicle maintenance and repair. Workers in manufacturing and in information and communications activities are also more highly susceptible to anxiety. Fatigue is most frequently reported by workers in public administration, defence and social security activities, followed by those working in the field of information and communications. Depressive reactions most frequently appear in construction, followed by catering and hospitality, and finance and insurance. Workers in information and communications activities and in transport most frequently report social behavioural disorders.

The overall psychophysical health average shows a similar trend, with the highest level of risk appearing in construction, information and communications, and finance and insurance. Those employed in electricity, gas and steam 
supply and in cultural, entertainment and recreational activities report the lowest levels of psychophysical risk.

\section{Conclusions}

Demographic variables are significantly linked to exposure to psychophysical risks. We can conclude that education acts as a safety factor, as the results indicate that more highly educated individuals less frequently report psychophysical health complaints (feelings of depression, anxiety, social contact issues). Age does not reveal any clear trends in relation to psychophysical health, but there are specificities regarding a specific age group in relation to the dimension. Sex explains the differences between individuals only in one of the dimensions; therefore, we cannot support the assumption that women are a higher-risk group when it comes to an understanding of their own health.

Of the professional groups or activities in which participants are employed, the research shows that workers in construction are most often exposed to psychophysical risks (they most commonly report physical health complaints and depressive reactions). Psychophysical health problems are also noted by workers in manufacturing (most commonly fear and anxiety), public administration, defence and social security (frequently fatigue), and information and communications (frequently social behavioural disorders).

Despite the suitably large sample, there were too few participants from some sectors (mining, agriculture, real estate) to enable a proper analysis. If the research were repeated, one could also ask participants about their status within the organisation (management/non-management staff) and on the number of days of sick leave per year. This information would provide us with an additional insight into the issue at hand.

The research has drawn attention to the large number of risks to which individuals are exposed at work, and could be of value in informing employers of the potential consequences of exposure to various risks among their employees. At the same time, the results could raise the awareness of employers in certain sectors: that the working environment is occasionally too demanding and that solutions and measures should be sought in a systematic, planned way (e.g. by adapting the workplace, providing psychological support, and education and training) to reduce psychophysical risks.

\section{References}

ALBREHT, T. in TURK, E., 2010. Ekonomsko breme duševnih bolezni. Zdravstveni vestnik, 78(7/8), 531-536.

BORG, V., KRISTENSEN, T.S. in BURR, H., 200o.Work environment and changes in self-rated health: A five year follow-up study. Stress and Health, vol. 16, No 1, pp. 37-47. 
BRAUNSBERGER, F., HLAVATY, M., SCHLAMBERGER, N. in STEVANOVIČ, S., 2008. Standardna klasifikacija dejavnosti 2008 [Last accessed: 3. 4. 2017]. Available at: http://www.stat.si/dokument/1209/skd.pdf.

BRUN, E. in MILCZAREK, M, 2007. Expert forecast on emerging psychosocial risks relater to occupational safety and health. Belgium: European Agency for Safety and Health at Work.

EVANS-LACKO, S., KOESER, L., KNAPP, M., LONGHITANO, C., ZOHAR, J. in KUHN, K., 2016. Evaluating the economic impact of screeningintreatment for depression in the workplace. European Neuropsychopharmacology, vol. 26, No 6, pp. 1004-1013.

FISEKOVIĆ, M.B., TRAJKOVIĆ, G.Z., BJEGOVIĆ-MIKANOVIĆ V.M. in TERZIĆ-SUPIĆ, Z.J., 2015. Does workplace violence exist in primary health care? Evidence from Serbia. European Journal of Public Health, vol. 25, No 4, pp. 693-698.

FRONE, M.R. in TIDWELL M.C.O., 2015. The meaning in measurement of work fatigue: Development in evaluation of the three-dimensional Work Fatigue Inventory (3D-WFI). Journal of Occupational Health Psychology, vol. 20, No 3, pp. 273-288.

GUDIPATI, S. in PENNATHUR, A., 2016. Workload assessment techniques for job design [Last accessed: 3. 4. 2017]. Available at: http://semac.org. $\mathrm{mx} /$ archivos/6-9.pdf.

HENDRIKS, S.M., SPIJKER, J., LICHT, C.M.M., HARDEVELD, F. , DE GRAAF, R., BATELAAN, N.M., PENNINX B.W.J.H., AARTJAN T.F. in BEEKMAN, A.T.F., 2015. Long-term work disabilityinabsenteeism in anxietyindepressive disorders. Journal of Affective Disorders, No 178, pp. 121-130.

HUPKE, M., 2013. Psychosocial risks and workers health. [Last accessed: 3 . 4. 2017]. Available at: https://oshwiki.eu/wiki/Psychosocial_risks_and_ workers_health

KUHTA, K., 2016. Vpliv delovnega mesta na psihofizično zdravje zaposlenih: diplomska naloga. Ljubljana: Filozofska fakulteta.

LONGO, L., 2016. Mental workload in medicine: foundations, applications, open problems, challenges and future perspectives. Dublin: Proceedings of the IEEE Syposium on computer based medical system.

MAJSTOROVIĆ, N., 2011. Skala psihofizičkog zdravlja. Unpublished material.

MORTENSEN, R., 2014. Anxiety, work and coping. The Psychologist-Manager Journal, vol. 17, No 3, pp. 178-181.

POPOV, B., MASTOROVIĆ, N., MATANOVIĆ, J., JELIĆ, D. in RAKOVIĆ, S., 2016. Predictors of employees' psychophysical health and sickness absenteeism: Modelling based on REBT framework. Psihologija, vol. 49, No 1, pp. 67-86. 
SPARKS, K., FARAGHER, B. in COOPER, C.L., 2001. Well-being and occupational health in the 21st century workplace. Journal of Occupational and Organizational Psychology, vol. 74, No 4, pp. 489-509. 